\title{
Teología de la liberación y cultura
}

\section{PEDRO TRIGO}

\section{Centro Gumilla, Caracas, Venezuela.}

El tema de la cultura en la teología de la liberación (TL) es complejo. Por una parte puede significar cómo ha influido la cultura latinoamericana, entendiendo por ella los productos y movimientos culturales latinoamericanos, en los autores de la TL y sus producciones escritas. Aqui se pregunta por la relación de la TL con expresiones ideológicas y especialmente con expresiones simbólicas de la élite. Una segunda consideración tiene que ver con la catalogación de la TL como objeto y movimiento cultural. La TL posee una factura y según ella se ubica dentro de un tipo determinado de productos culturales. ¿Coincide esta ubicación con la intencionalidad de sus autores? ¿Puede observarse un proceso, un desplazamiento de la TL en el espectro cultural? Estas cuestiones previas nos colocan ante el verdadero problema cultural de la TL: ¿logrará transformarse en cultura popular? ¿Cabe en la cultura popular una transformación que asuma de algún modo la modernidad sin diluirse en ella? El encuentro de la propuesta de TL con la religión del pueblo, parte medular de la cultura popular, ¿a dónde está conduciendo?

\section{La cultura progresista ilustrada en la TL}

\section{Presencia de expresiones ideologicas}

La TL iha sido influida por los productos culturales de las élites latinoamericanas? $\mathrm{Si}$ nos atenemos a las producciones escritas de TL, las referencias a la producción simbólica latinoamericana son más bien escasas, aunque es bien perceptible la presencia de la producción ideológica latinoamericana. Creemos que esto vale como apreciación global y más aún como caracterización de las primeras producciones de TL que de algún modo crearon su imagen pública.

En dichos escritos es palpable la abundancia no sólo de citas, sino sobre todo de enfoques y más aún del pathos de la teoria de la dependencia y más en general del ambiente político de izquierda. Aunque en estos casos más que de influencia habria que hablar de impregnación ambiental y de coincidencia con un modo de ubicarse y reaccionar ante la situación latinoamericana. Incluso habría que referirse a corrientes de inspiración cristiana (es el caso de Paulo Freire) que coadyuvaron a la gestación de la TL y también influyeron en otros 
ámbitos de las ciencias sociales y la praxis social latinoamericana. El espectro que va de las últimas tesis de la CEPAL a la teoría de la dependencia como critica y alternativa a las tesis estapistas de Rostow que estaban a la base de la Alianza para el Progreso, eran una referencia obligada en unos años de ajuste de cuentas no sólo con esa teoría sino con esa política fracasada. Así aparece claramente en medellín y no podía dejar de señalarse con energia en los primeros trabajos de TL que trataban de esbozar diagnosticos y abrir perspectivas. Estas no podian abrirse de espaldas a las tesis que manejaba por entonces la izquierda latinoamericana. $Y$ asi el socialismo de rostro humano del Che; el historicismo gramsciano y su preocupación por la sociedad civil, el bloque histórico y el intelectual orgánico: el estructuralismo althuseriano y su énfasis en la ruptura epistemologica... dejan huellas evidentes en estos escritos de TL, no en el sentido de que los integren dentro de su escuela, sino de que suministran conceptos y enfoques que ayudan a los teólogos a sistematizar su pensamiento y más aún a hacerlo comprensible a su época (aunque de ningún modo quede reducido a sus parámetros). En esta época da que pensar el fenómeno de la guerrilla y muy en particular las propuestas, el camino y el destino de Camilo Torres; los argentinos son muy sensibles al peronismo como matriz cultural; los chilenos viven el contexto de la Unidad Popular; los peruanos, además de tener que definirse respecto a la revolución velasquista, se enfrentan al desafio de Marlátegui de transformar el marxismo leyéndolo desde la cuestión indigena (y campesina) y el del primer Haya sobre determinación de sujeto histórico y la necesidad de frentismo...

Otra determinación ideológica ambiental sería la superación del concepto y sentimiento de periferia respecto del centro y la necesidad de redefinir el estatuto cultural respecto del occidente. Esta urgencia de la "segunda independencia" es tematizada desde diversas instancias y una de ellas es, sin duda, la TL. En estrecha vinculación con ella, aunque en buena medida originada independientemente, está la filosofia de la liberación. Los contactos con la TL más que a través de su expresión mexicana (Zea y su grupo) se dan en su vertiente peruana (A. Salazar Bondy, Miro Quesada) y sobre todo Argentina en la que dos de sus más destacados representantes (Dussel y Scannone) lo son a su vez de la TL. A la larga podemos decir que, por el mayor desarrollo alcanzado, ha influido más la TL en la filosofia de la liberación que a la inversa.

\section{Presencia de expresiones simbolicas}

También podemos hablar de confluencia histórica, más que de influencias textuales o biográficas, en el caso de la TL y la nueva narrativa latinoamericana. Esta coincidencia ha sido reconocida con gusto por varios de los interesados de ambas partes y antes que a propuestas concretas se refiere a una misma actitud fundamental respecto del pueblo latinoamericano (de carino, de respeto, de indagación, en el fondo de reconocimiento de su consistencia) y una apuesta compartida por su liberación. Naturalmente que a este nivel unos autores (Borges, Donoso y a pesar de su testimonialismo Cortázar y Sábato) quedan más tangenciales, en tanto que otros (Roa Bastos, Garcia Márquez, Rulfo, Asturias, Conti, Arreola) aparecen más cercanos. Alguno coincide en el 
mundo al que se refiere, pero no tanto en sus connotaciones y proposiciones (sería el caso de Vargas Llosa). En otros el acuerdo es más bien a nivel ensayístico (C. Fuentes). Es cierto que también puede hablarse de relación biográfica e influencia (Roa Bastos-Meliá, Leñero CRT) e incluso de referencia mutua estructural (Arguedas-G. Gutiérrez). A veces es más bien el magisterio intelectual de una personalidad (por ejemplo Marechal entre los argentinos). En casos de promociones más recientes podría hablarse ya de gravitación en una zona común (Galeano, Skámeta, el poeta Cisneros). Incluso hay ya novelas motivadas en parte por el proyecto pastoral de la TL (Redoble por Rancas, Megafón o la guerra, De amor y de sombra). Más aún se da la novela cuyo tema y perspectiva es el evangelio leído desde la TL (La piedra que era Cristo). Incluso existe una obra de teatro que es a la vez un eximio producto artistico y TL, no sólo por el tema sino por la perspectiva y elaboración (Golpes a mi puer(a). El caso más llamativo sería el de E. Cardenal que como poeta y militante (ya que no como intelectual, como teólogo) está dentro de la TL y ocupa un lugar señero en la poesía latinaomericana.

Habría paralelismos mucho más sutiles, pero tal vez por eso más profundos. Seria sugerente, por ejemplo, relacionar el modo concreto como L. Boff desgrana la humanidad de Jesús, las cualidades que más le llaman la atención. (Jesucristo libertador, cap. V) con los denominadores comunes de los personajes más positivos de la impresionante galería que pinta J. Amado en sus novelas. Incluso si nos fijamos en la propuesta antropológica del teólogo brasileño (Ternura y vigor) ¿no habria que resaltar que, amén de cristiana y franciscana, trasunta el ideal de la cultura brasileña?

Cabria igualmente una aproximación entre la actitud lúcida, marginal, incesantemente desmixtificadora del teólogo uruguayo J.L. Segundo y la de su compatriota el gran narrador J.C. Onetti.

\section{Presencia de la cultura occidental}

Pero hasta hoy la referencia fundamental de las producciones de la TL siguen siendo (como era de esperarse) los teólogos, sobre todo europeos, y las referencias culturales que derivan de la ilustración. Naturalmente que estas referencias no se asumen acríticamente: se trata de entablar con ellas un diálogo desde América Latina como situación y experiencia, como lugar epistemológico. Pero hay que reconocer que en el diálogo el occidente ha estado demasiado presente. Sin duda la necesidad apologética de cara a la institución eclesiástica central, a los colegas europeos y en general a la opinión pública cristiana de Europa y Estados Unidos ha acentuado esta tendencia. Pero ella estaba ya en los autores; aunque en el curso de estos quince affos se observa un desplazamiento lento y consistente hacia la referencia latinoamericana no como ensimismamiento o chauvinismo, sino como necesidad epistemológica.

Creemos que la producción tan polifacética de Dussel puede ilustrar esta dúplice aspiración a la autonomía y al reconocimiento. Sin duda que el objetivo es encontrar la propia perspectiva, indagar desde ella y nombrarse creadoramente. Pero esto no se hace sólo a partir del ancestro indigena y la praxis de 
nuestros pueblos y sus aliados. Hay que "destruir" en todos los frentes la estructura colonial. Y a ello se aplica con tan absorbente celo que hace pensar en una secreta fascinación (más palpable todavia en su reciente descubrimiento de Marx). Naturalmente que Dussel evidencia una formidable capacidad de relectura, porque es profundo su anclaje en la perspectiva del pueblo creyente y oprimido, pero la referencia al occidente se mantiene aún como dominante.

Insistimos en que aqui tratamos de las referencias textuales no de la referencia fundamental que es la realidad latinoamericana entendida como lugar teológico. Jon Sobrino, por ejemplo, fuera de los teólogos, apenas si nombra a ningún autor latinoamericano, y sin embargo, su obra teológica está absolutamente marcada por la muerte como opresión que sufre el pueblo salvadoreno y por su justa lucha por vivir. Sus producciones teologicas estan cada vez más absorbidas por esta situación que no sólo le da los temas, sino aun muchas de sus categorias teológicas que brotan de su capacidad creadora y de las practicas del "cuerpo históríco de Cristo" crucifícado de nuevo, del que el teólogo es servidor.

\section{La TL como parte de la cultura progresista ilustrada}

\section{Reconocimiento y sentido de una cotradicción}

La TL a nivel formal nace como un producto universitario: lenguaje, metodologia, aparato crítico, destinatarios. Incluso algunos de sus libros más representativos fueron originalmente tesis presentadas en facultades europeas. Pero la relación va más allá de la mera formalidad. La TL es interdisciplinar; de un modo genérico o preciso y aun muy pormenorizado, las obras de TL se sitúan expresamente (ya lo hemos indicado más arriba) como parte de la cultura progresista ilustrada de América Latina. Se puede señalar, pues, una contradicción entre el contenido de la TL (el pueblo como sujeto histórico en la sociedad y en la Iglesia) y su estructura (obras de élite que sólo la élite puede leer). Hay que decir que esta contradicción está expresamente reconocida y su resolución se encomienda al proceso. Por eso, la TL se autoentiende como de transición. Y que esto no sea una mera proclamación vacía se deja ver en el corrimiento que efectivamente ha tenido lugar en tan poco tiempo.

Pero además esta contradicción expresa la situación inicial: el movimiento pastoral que está a la base de la TL funciona por una alianza de sectores medios con el pueblo. Esta alianza funcionaba de hecho en todos los movimientos revolucionarios latinoamericanos contemporáneos al surgimiento de la TL, pero generalmente se declaraba inexistente por un mimetismo que escondia y salvaguardabe la manipulación y el dominio de estos grupos sobre los elementos populares o bien se mantenia la supremacía latente desplazándola a otro nivel conceptual, por ejemplo, el partido (controlado por las élites) como vanguardia del pueblo. La TL proclama abiertamente la existencia de esta alianza para que, reconocida, pueda ser custodiada de modo que el servicio de las élites no se pervierta en supremacía injusta. Así, pues, la TL es la proposición provisional que las élites aliadas al pueblo creyente y oprimido presentan como comprensión y relanzamiento de la práctica común (en la que el pueblo tiene la 
parte principal). En esta proposición el pueblo creyente y oprimido no es sólo el contenido principal, sino también es en buena medida el sujeto de ese contenido. Pero el teólogo (con su carisma especial y sus limitaciones) es el último responsable hoy por hoy de las producciones de la $\mathrm{TL}$. Y hay que reconocer que todavía el pueblo creyente y oprimido y las comunidades no están en condiciones de controlar esta mediación de los profesionales de la teologia y ni siquiera constituyen su destinatario inmediato.

\section{Ilustración y pueblo en América Latina: solidaridad y desencuentro}

De este modo las producciones de la TL se sitúan entre las producciones de las élites latinoamericanas ilustradas: la de los ideblogos revolucionarios que prepararon, realizaron y justificaron no sólo el proceso emancipador, sino el intento de superar el orden colonial latifundista, esclavista y estamental; la de los liberales populares y socialistas utópicos de mediados del XIX; la de los que, cuando hacia 1880 se consumaba la moderna división internacional del trabajo, se rebelaron contra el neocolonialismo y el colonialismo interno; la de los que pretendieron superar creativamente el positivismo justificador del (des)orden establecido como (imposible) camino de progreso; la de los revolucionarios de nuestro siglo, empezando por los escasos que trataron de alumbrar sin desvirtuar a la revolución mexicana, los de la reforma universitaria de Córdoba, los indigenistas, agraristas, obreristas...

Estas producciones ilustradas revolucionarias nacieron de la solidaridad con los pueblos latinoamericanos llevada frecuentemente hasta el sacrificio de la vida. La autenticidad de ese compromiso se evidenció también en el amor concreto, no sólo cordial, sino estimativo y valorativo al pueblo en sus rostros diferenciados. Más aún el compromiso popular se plasmó en ciertos casos en la originalidad de las propuestas que nacían asi en buena medida de la práctica compartida. Pero hay que reconocer que la mayor parte de esta literatura se destinaba a ganar a gente no popular para la causa del pueblo. No era únicamente que en un continente de analfabetas ése era el único destino razonable de la producción escrita. Era tambien el convencimiento de que el pueblo no podría levantarse por sí solo: estaba tan postrado que no tenía fuerzas fisicas ni recursos económicos y organizalivos ni objetivos y horizontes precisos. La revolución tendría que ser comandada por otros sectores y asi a ellos ante todo debia ser propuesta. No se trata ciertamente de las tesis del despotismo ilustrado: el objetivo era contar cada vez más con el pueblo. Y por eso estos intelectuales siempre hablaron tambièn al pueblo e hicierron muchas propuestas concretas para aumentar su capacitación y su participación efectiva. Pero creemos que, globalmente consideradas, estas propuestas se inscribian en la Ilustración (la liberal y después la socialista) como variantes internas y por lo tanto incluían de uno u otro modo la aculturación de los pueblos latinoamericanos.

Del rechazo a la búsqueda de un lugar de encuentro

Creemos que esta aculturación se ha dado en algunas capas del pueblo y 
en todas, más o menos, por lo que toca a algunas actitudes y elementos. Pero después de dos siglos de propuesta ilustrada en América Latina puede afirmarse que la cultura popular ha resistido en buena medida a la matriz cultural de la Ilustración. $Y$ no por falta de proposicion o por cerrilidad, sino por positivo rechazo. Creemos que a esto hay que atribuir la esterilidad de muchos de los mejores esfuerzos del XIX y de las primeras décadas del XX, y de un modo muy particular ahí habrá que buscar la causa del fracaso de las diversas propuestas maxistas en América Latina. Claro está que no podemos olvidar el intervencionismo de Estados Unidos y la represión de las oligarquias y burguesías. Pero no podemos decir que el problema haya sido la derrota en confrontaciones abiertas, sino la falta de capacidad de convocación (tal vez la excepción sea Chile); se ha llegado a la confrontación cuando la inspiración marxista no ha sido sentida como la dominante (Cuba 1958, Bolivia 1952 y 70, Santo Domingo 1965, Nicaragua 1979...)

Ha resultado trágico para América Latina que las élites tuvieran que salir de la ecumene colonial en la segunda mitad del XVIII. La causa estaba en que esa cultura barroca', si daba vida, cada vez dio menos luz. Que esa luz se buscara en otra parte y que con ella se negara el propio ser cultural en vez de dialogar con él y transformarlo desde dentro fue una tragedia para la intelectualidad y para el pueblo latinoamericano. Divorciados ambos intelectualmente no lograron fecundarse mutuamente. El impasse de buena parte de la izquierda latinoamericana en el momento actual debe ser interpretado como el fin de este camino bisecular.

Siempre ha habido intentos por restablecer la comunicación desde unas bases que superaran ampliamente la aculturación. Muchas propuestas se han nucleado en torno al mestizaje cultural. Sin embargo, en la mayor parte de ellas la cultura occidental fungia como elemento dominante y las otras culturas como elemento recesivo, cuando no meramente folklórico. A veces se apreció en mucho el aporte popular, pero como savia fresca más que como dirección y contenidos. De todos los modos hoy sí está expresamente propuesto el acercamiento integral.

\section{La TL: propuesta de diálogo histórico}

En este contexto la TL (como movimiento y como producciones) sería el intento más coherente y dinámico de tender el puente, roto hace dos siglos, entre el pueblo y la intelectualidad progresista en América Latina. Por eso su proposición básica sería el diálogo histórico. Diálogo entre la cultura ilustrada y las culturas populares, desde el pueblo creyente y oprimido, desde su resistencia y sus luchas por la liberación. Un diálogo que cada día se realiza más en la casa del pueblo, no sólo en su medio fisico, sino en su medio cultural. Un diálogo abierto en el que no se pretende ni la aculturación del pueblo ni el mimetismo populista de las élites. Diálogo histórico porque sus portadores no son individuos del mismo conjunto, sino portadores de universos culturales en parte comunes (cristianismo, América Latina, liberación) y en parte divergentes (Ilustración-culturas indigenas, campesinas, suburbanas, populares). Diálogo histórico porque histórica es su longitud de onda: será cuestión de ge- 
neraciones porque una proposicion no se lanza socialmente en menos de una década y no se puede comprobar y asumir y transformar en menos de dos 0 tres más.

Pero este diálogo histórico se realiza sobre todo de un modo oral. Cuando se escribe son generalmente breves pautas para la discusión, apuntes sobre una situación o coyuntura, resúmenes, oraciones y cantos... mimeografiados. Es la cultura fugaz del mimeógrafo que tantos instantes apresa y luego relega al olvido. En los libros (como en este artículo) puede aludirse a este diálogo histórico, pero él no acontece por lo regular en estos cauces. Lo que no quila que en los libros pueda codificarse (por lo menos en la versión de una de las partes) lo ya adquirido, plantearse hipótesis sobre los pasos que faltan y discutirse muchos problemas teóricos sin duda relevantes para él.

\section{El diálogo en la propia orilla}

Pero si el libro de teología no se presta aún por lo general para este diálogo histórico sí puede cumplir y está cumpliendo con gran responsabilidad otra tarea previa: la de afinar sus proposiciones de modo que el teólogo de la liberación resulte efectivamente portador histórico tanto como hombre de Iglesia como en cuanto intelectual latinoamericano. Es esta una tarea delicada: homologar su proceso y propuesta con las de la Iglesia 'madre' de modo que por un lado se conserve la genuinidad y por otro sea reconocida como católica no es fácil en los tiempos que corren, más dados a la uniformización dominadora que a la comunidad católica. Tampoco resulta fácil compaginar esta preocupación eclesial con la de dialogar desde dentro con el resto de la cultura ilustrada progresista latinoamericana, su enemiga secular. En no pocos momentos ambas preocupaciones tienden a desgarrar a los teólogos ya que cada uno de los bandos tiende a considerarlos como representantes infiltrados del otro. A pesar de eso se va tendiendo el puente aunque no muchos lo consideran seguro ni menos se atreven a transitarlo. Creemos que esta preocupación "pontifical," revestida no pocas veces de formas polémicas que dificultan reconocerla, es un aporte realmente histórico de esta corriente cultural. $Y$ aunque sólo fuera por eso debería encontrar el reconocimiento de tantos que la denigran desde una terca e infecunda cerrazón en un pasado agotado e injusto desde el que, como el siglo pasado en Europa, luego se lamentarian de la apostasía de las masas y de los intelectuales sin percatarse de que son ellos quienes los están abandonando por no aceptar otra relación con ellos que el señorío feudal.

\section{El problema de la cultura en la TL}

\section{La pregunta por el pueblo como sujeto cultural}

La TL propone, como novedad histórica fundada en el evangelio, pero no deducida sin más de él, la constitución del pueblo como sujeto histórico tanto en la sociedad como en la Iglesia. Esta proposición se degradará a mera proclamación de principios si la TL no asume formas de la cultura popular 
transformándose y transformándolas. De que se dé o no este pasaje cultural depende el que la TL realice sus proposiciones básicas o quede confinada a su forma inicial, una manifestación más de las élites latinoamericanas.

Esta proposición supone que podamos responder a estas preguntas: ¿el pueblo latinoamericano es sujeto cultural? ¿Existe la cultura del pueblo bajo otra forma que la cultura tradicional más o menos residua? La asunción de la modernidad ¿no supone el fin de la cultura popular? ¿Hay posibilidad de asumir la modernidad sin la hegemonía de la burguesía? ¿Hay posibilidad de una alternativa revolucionaria en América Latina que no sea una diferencia interna de la sociedad occidental y que no lleve por tanto a la occidentalización y con ello al fin de la cultura popular? Si asi fuera la TL no seria el tránsito hacia la plena expresión del pueblo creyente y oprimido de América Latina sino la mediación hacia la occidentalización: llegados al poder, sus fautores regresarían a una teología del desarrollo, y de ahí a las teologias de Europa y Estados Unidos.

Hay que confesar que estas preguntas no están aún respondidas. Y no por falta de indagación, sino porque los pueblos latinoamericanos se encuentran en pleno proceso y las direcciones de ese proceso son múltiples. En primer lugar, existe el proyecto cultural trasnacionalizador que pretende uniformar arrasando toda cultura particular. Se trata de convertirnos a todos en consumidores de lo que ellos producen. Están también las propuestas de la cultura dominante, que integra, folklorizándolos, algunos elementos de la cultura popular, pero negando al pueblo como sujeto cultural. Ciertamente que ambos proyectos encierran un elemento al que el pueblo no está dispuesto a renunciar: los adelantos del mundo moderno y los mecanismos que conducen a ellos. No se trata únicamente de la fascinación de los aparatos y la tendencia a jurungarlos. El pueblo se disciplina para poseer el secreto de la máquina. En unos para cambiar de piel. En otros para poder vivir y para vivir mejor, pero desde ellos mismos. ¿Cuál de ambas direcciones acabará imponiéndose? Desde luego que hoy no resulta tan claro decir, como pareció a muchos obvio a principios de los 60 , que los pueblos latinoamericanos acabarán por integrarse sin más a la "sociedad occidental y cristiana." No sólo que no es económicamente posible. Sino que se va abriendo paso un proyecto alternativo.

\section{El pueblo como productor actual de cultura}

Si por cultura entendemos la producción, socialmente organizada, de la vida humana, tenemos que decir que en América Latina la cultura popular no es sobre todo, ni siquiera en los países andinos o en el altiplano mexicanoguatemalteco, el sustrato tradicional heredado, con ser éste a veces tan denso y fecundo. Lo más decisivo de la cultura popular es lo que en estas décadas estan produciendo nuestros pueblos. Voy a ejemplificarlo con el caso de Venezuela. En estos cuarenta años Venezuela ha pasado de un 20 a un 83 por ciento de población urbana. No ha sido un éxodo planificado. Cada quien fue por su cuenta. Tuvo que invadir un pedazo de tierra para construir él mismo su casa, conseguir un trabajito hasta lograr una relativa estabilidad y especialización, luchó por los servicios fundamentales, consiguió sacar adelante a la familia, 
algunos hijos hasta se graduaron en la universidad, encontró algunos amigos fieles y edificó poco a poco una comprensión de lo que le había sucedido, de lo que estaba sucediendo y aun conceptos generales del mundo y de la vida. Este modo humano concreto de producir la vida ino constituye una cultura? Poco a poco este sustrato cultural se va expresando simbólicamente: es la cultura en sentido restringido con perfiles cada vez más definidos y cualificados.

\section{La práctica del diálogo}

Nosotros ciertamente tenemos que dialogar con la cultura tradicional: es el punto de partida de este proceso y aflora de mil modos en él. También con las culturas campesinas. Pero en Venezuela no cabe duda que esta cultura naciente es el interlocutor y destinatario principal de la TL. Y hay que decir que tanto el desarrollismo del proyecto pastoral de promoción popular como el proletarismo de la izquierda cristiana desconoció la entidad cultural de estas personas a las que consideró simplemente como marginados del mundo moderno o como explotados por el sistema, pero no como sujetos históricos de un verdadero éxodo. Y este éxodo ha ocurrido; en el sentido de movimientos de pueblos, en el de trasculturización y en el sentido teológico de paso de unas condiciones de vida menos humanas a otras más humanas (Medellín: Introducción, 5). Creemos que en toda América Latina este éxodo es un hecho fundamental y que efectivamente puede ser entendido como el paso de un lugar donde no había vida ni frecuentemente horizonte, aunque si muchas veces sentido, a la construcción de otro en el que la vida se va abriendo paso, va naciendo un horizonte y se lucha vigorosamente por dar sentido a la vida.

Hay que reconocer que la Iglesia no acompañó los pasos de los primeros peregrinos ni estuvo presente y de su parte en los primeros asentamientos. Muchas veces llegó cuando el barrio había adquirido ya forma. Pero desde hace $10 \delta 15$ años no puede decirse lo mismo. La presencia de agentes pastorales es un hecho contundente en los barrios de América Latina. Y aquí sobre todo se ha instaurado el diálogo histórico. Porque los agentes pastorales no aparecen como funcionarios de la institución que distribuyen "paquetes cerrados," que disciplinarmente "bajan la línea" a las bases. Gracias a Dios en América Latitina ha fracasado la pastoral de conjunto entendida como la llamada a que todos pongan en práctica lo que elaboró un comité central, un "cogollito" en un cenáculo cerrado. Los agentes pastorales no llevan tesis, sino muchas preguntas y algunas propuestas y por supuesto el evangelio de Jesús que (a diferencia de la "doctrina cristiana") no es un humanismo Todo es materia de diálogo y va siendo reelaborado poco a poco a través de él: la espiritualidad, los modelos de santidad, el diseño sacramental y devocional, las prácticas históricas, las conductas cotidianas... Esto es lo que constituye el problema cultural de la TL. Y no sólo de la TL, porque de que estos pueblos creyentes y oprimidos logren plasmar genuinamente éste su modo humano de vivir, de la validez cristiana de esta propuesta y de su reconocimiento por otras iglesias y especialmente la de Roma depende de la catolicidad de América Latina.

Si es cierto que en América Latina lo más decisivo de la cultura popular se juega en la cultura que hoy se crea (como reacomodo, resistencia y alternativa 
a la cultura dominante) esto significa que el diálogo histórico en que se expresa la TL gira sobre todo alrededor de la praxis: praxis para defender la vida y custodiar su dimension sagrada y compartida, praxis para celebrar esta vida, y praxis histórica para liberarla, para resistir, para avanzar hacia una reestructuración más humana. La praxis es lugar privilegiado porque en sí lo es: porque en ella reluce la realidad y el propio sujeto sabe quién es. La praxis es lugar privilegiado porque también lo es para el pueblo: el pueblo piensa haciendo, se conoce haciendo, se expresa concreta y activamente; su palabra quiere ser teoría: comprensión de la práctica. La praxis es lugar privilegiado para el diálogo por que en ella nos encontramos con el pueblo creyente y oprimido: ahi se da el lugar común de donde puede brotar una palabra compartida. Sólo nuevas experiencias darán lugar a expresiones religiosas más globales y claramente liberadoras.

Pero, hay que insitir, esta praxis no puede atarse a un plan predeterminado ni a un partido. Debe estar anclada en la cotidianidad para que no se pervierta. No hay diálogo cutural desde el activismo militante que todo lo polariza y que obstruye la espontaneidad y el pluralismo. El humus imprescindible es el tiempo abierto de la convivencia, el estar-con y estar-en, dimensiones mucho más profundas que cualquier actividad pautada.

Este diálogo se realiza en tres dimensiones: la grupal (sobre lodo a través de las CEB), la interpersonal y la masiva. Estas dos últimas cada vez son más tenidas en cuenta.

\section{Las manifestaciones simbólicas}

De este diálogo cultural asi concebido, que privilegia la religión del pueblo, pero que no se reduce a ella, empiezan a brotar manifestaciones culturales simbólicas cada vez más genuinas, acendradas y valiosas. $Y$ las fuentes son muy dispares. Están los miles de cantos que se desgranan por todo el continente sin recogerse aún en cancioneros estables, los sociodramas, los vía crucis, los murales, pancartas... Son ya muchos los encuentros cristianos que constituyen además acontecimentos culturales inolvidables, no sólo por el hondo sentir, sino por la "puesta en escena" tan creativa, sencilla y brillante. Especial mención merecen los catecismos ya absolutamente inculturados y hermosos en su sencillez. Vamos caminando (del equipo pastoral de Bambamarca-Perú) catecismo para campesinos adultos de la sierra y Nosotros (del barrio de Guachupita, República Dominicana) dedica a los niños del barrio caribeño, constituyen dos ejemplos complementarios. Entre las misas queremos destacar la salvadoreña, la nicaragiense y las dos brasileras (la de "los Quilombos" y la de "La tierra sin mal"). En la ilustración la mención obligada es la de Cerezo Barredo, creador de una iconografia inequivocamente caribeña, popular, cristiana y desde luego hermosa. Han alcanzado también indudable personalidad los pintores de Solentiname, que pueden representar tantos otros intentos exitosos de expresión popular cristiana liberadora. Habría que mencionar a los Cristos cuzqueños de Mérida y su escuela, a los esmaltistas salvadoreños... 
Pero la mayoria de edad de este diálogo cultural se evidencia cuando desde el lado de la cultura popular se percibe este proyecto y se lo integra desde sus propios vehículos expresivos. Es el caso del cantautor venezolano, trágicamente fallecido, Ali Primera. O del exitoso long play de Rubén Blades, Buscando América. No sólo que uno se reconoce plenamente en los dos temas sobre los desaparecidos o en el que da el título al álbum, sino que el número "El padre Antonio y su monaguillo Andrés" tematiza el camino y el destino que autentica a la TL: homenaje a nuestros mártires que conjuga la narración desde la cotidianidad (sin sacrificar la lucidez) con el canto a la esperanza de nuestros pueblos en el que a Пora el nombre señero de "un cura bueno" Oscar Arnulfo Romero.

Desde el punto de vista de los teólogos hay que destacar el esfuerzo de los brasileros, empezando por L. Boff. por escribir de un modo asequible y gustoso para el pueblo. En Brasil se escribió la primer pastoral que conozco dirigida directamente al pueblo y por eso en su lenguaje (El grilo de las iglesias, 1973). Modelo de este diálogo cultural lo constituyen los libros de C. Mesters en los que el pueblo oprimido y creyente vuelve a ser protagonista de la Biblia y la reescribe en fidelidad abierta y creadora. No podemos dejar de mencionar el caso de $\mathbf{P}$. Casaldáliga, pastor-poeta y animador humilde y generoso de tantas iniciativas de diálogo cultural y plasmador de tantas expresiones simbólicas.

De Perú, más que el aspecto formal (ver, sin embargo, la 3ra. parte de Beber en su propio pozo), vale sobre todo el ingente esfuerzo analítico por encauzar este diálogo y llevarlo a cabo. Es impresionante el número de publicaciones periódicas especializadas producidas y asumidas por organizaciones populares dentro de la corriente de la TL.

Los argentinos han demostrado una gran sensibilidad hacia el tema de la cultura dentro del proyecto cristiano liberador. Es el tema sobre el que siempre vuelve Scannone, cada vez más preciso y encauzado, aunque tal vez un tanto escaso de mediaciones analiticas. Ya nos hemos referido a Dussel, del que habria que reseñar además su esfuerzo como historiador y animador del grupo CEHILA, Gera y Zaspe han ligado la cultura al análisis de religiosidad popular; ellos tuvieron mucha influencia en los documentos de Puebla sobre ambos temas.

Los mexicanos han demostrado sensibilidad creciente hacia este diálogo cultural y nos han proporcionado valiosos análisis, desde la canción popular a la Virgen de Guadalupe. Pero, sobre todo en el área indigena, han avanzado en la práctica de este diálogo que llega a manifestarse incluso en la estructuración completa de algunas diócesis.

El balance sigue abierto. 